\title{
LA LEY APLICABLE AL CONTRATO INTERNACIONAL ENTRE PARTICULARES EN EL PROYECTO DE TITULO PRELIMINAR DEL CODIGO CIVIL PERUANO
}

\author{
Delia Revoredo de DeBakey
}

En febrero de 1977, en la Revista de Jurisprudencia Peruana, se dió a publicidad el Proyecto del Título Preliminar del Código Civil y su correspondiente Exposición de Motivos, ${ }^{1}$ elaborados por la Comisión Reformadora del Código Civil. ${ }^{2}$

El articulado del Título Preliminar se divide en dos capítulos, conteniendo el segundo, las reglas propias del Derecho Internacional Privado, las que han sido concebidas desde una perspectiva totalmente innovadora, tanto en lo que respecta a la sistemática empleada como a la selección de las categorías y disposiciones normativas.

Agradecemos este importante y meritorio aporte que la Comisión Reformadora del Código Civil hace al país en general, y a los estudiosos del Derecho en particular, ya que, en razón de la perspectiva innovadora a que hemos hecho referencia, constituye una interesantísima invitación a reflexionar sobre las modificaciones y ampliaciones propuestas, tales como el régimen dispositivo sobre las cuestiones del Derecho de Familia - el Proyecto les dedica quince artículos, mientras que el Título Preliminar del Código Civil vigente, uno - o los nuevos y más ordenados criterios utilizados en el Proyecto para atribuir la competencia jurisdiccional a los Tribunales peruanos.

No es nuestra intención, en este trabajo, comentar todo el sistema elaborado por la Comisión para resolver conflictos de leyes. Hemos elegido una sola de las disposiciones presentadas en el Proyecto, relativa a "la ley aplicable a los contratos internacionales", cuestión vinculada a otras dos novedades legislativas: la referencia expresa al fraude a la ley y la determinación de la imperatividad de 1. "R⿳亠丷厂巾ista de Jurisprudencia Peruana", No 397, Lima, febrero de 1977, págs. 349 y siguientes.

2. La Comisión Reformadora fue creada por D.S. $N^{\circ} 095$ del 1ro. de marzo de 1965. Participaron los señores doctores Max Árias Schreiber Pezet, Jorge Avendafio Valdez, Ismael Bielich Flórez, Héctor Cornejo Chávex, Alberto Eguren Bresani, Carlos Fernández Sessarego, Manuel Garcf́a Calderón Koechlin, Rómulo E. Lanatta Guilhem, José León Barandiarán, Felipe Osterling Parodi y Jorge Vega Garclá. 
las normas por la ley que resulte aplicable, En este trabajo segu uremos por tanto el siguiente plan:

1. Campo de aplicación de las normas pertinentes

2. Contratos nacionales e internacionales. Mètodos para regularlos

3. Régimen actual

4. Régimen adoptado en el Proyecto

4.1. Las partes pueden elegir la ley del contrato. (Art. XLIII)

4.2. Las partes no pueden eludir la ley peruana competente. (Art, XVI)

4.3. La ley elegida determina la imperatividad de las normas y los limites a la libertad de contratación. (Art。XLIV).

5. Sugerencias.

\section{CAMPO DE APLICACION DE LAS NORMAS PERTINENTES}

Al presentar el Proyecto en su Art. XLIII un tratamiento distinto al de los regimenes adoptados por el Perí en el Tratado de Montevideo y en el Código de Bustamante o Tratado de La Habana y al reformar aparentemente al Código Civil vigente en el aspecto de la ley aplicable a los contratos internacionales entre particulares, hemos considerado oportuno comentar comparativamente lo que disponen el Tratato de Montevideo de 1889, el de La Habana de 1928 y el Código Civil Peruano de 1936, por un lado, y el Proyecto de Reforma del Código Civil Peruano recientemente publicado (1977), por el otro, a fin de resaltar las bondades o las dificultades que puedan derivarse de esta innovación legislativa.

Es de suponer que el novísimo sistema plasmado en el Proyecto de-Reforma del Código Civil contiene una mejora normativa respecto a los regímenes contemplados en los demás textos legislativos citados. Debe notarse sin embargo, que esta innovación normativa, si bien se efectivizaría dentro del campo de aplicación que tiene el Código Civil vigente (pues el Proyecto, de aprobarse, lo suplantaría en lo que lo reforma), no podrá en cambio efectivizarse en el campo de aplicacion que tienen los Tratados Internacionales suscritos y ratificados por el Perú, y que constituyen un compromiso multinacional que no puede modificarse en cuanto a su vigencia internacional y a su obligatoriedad para los paises que lo asumieron, por la voluntad unilateral de uno solo de los países firmantes. El nuevo Código Civil mantendrá pues una vigencia paralela y contemporánea con dichos tratados. 


\section{CONTRATOS NACIONALES E INTERNACIONALES. METODOS PARA REGULARLOS.}

A la finalidad de este trabajo, conviene recordar que los contratos pueden ser nacionales o internacionales; que los primeros tienen todos sus elementos esenciales nacionales, interesan a un sólo país y se rigen por el Derecho de tal país; mientras que los segundos, a los cuales nos referiremos en este trabajo, no tienen todos sus elementos nacionales, ni afectan exclusivamente a un sólo país sino a varios. Es entonces que se presenta el problema de determinar el derecho de qué pais, entre los varios involucrados, debe regular tales contratos.

Conviene también apreciar en su enorme dimensión la importancia de determinar con propiedad la ley aplicable a los contratos internacionales, pues resulta indiscutible la gran influencia que tienen sobre el comercio internacional y la economia de los países.

En teoría, el régimen de los contratos internacionales puede quedar establecido de dos modos:

a) A través de un derecho nacional, que sirviéndose de una norma de conflicto señale la ley aplicable a los contratos, utilizando diversos criterios vinculatorios con los parses, tales como la celebración del contrato o la ejecución del mismo, en cuyos casos la ley aplicable será la del país donde se celebró el contrato o donde éste se ejecutó.

Como el contrato internacional implica un conflicto entre las leyes de varios países involucrados en la relación contractual, la norma de Derecho Internacional Privado del pais del juez debe resolver tal conflicto, eligiendo una de esas leyes y descartando a las demás.

Debemos considerar, el lado de esta posición, una que siendo igualmente "nacional" resulta distinta: la teoría de la autonomfa de la voluntad que, de permitir a las partes elegir un derecho completamente ajeno al contrato para que lo regule, hace innecesaria la norma de Derecho Internacional Privado, que sirve para asignar al contrato una ley determinada por el legislador.

Debe pues, ante todo, averiguarse si el Derecho Internacional Privado del juez competente, permite a las partes que celebran un contrato elegir o no la ley que debe regularlo, ya que de ello depende el carácter subsidiario o imperativo de las demás disposiciones del Derecho Internacional Privado del juez. Si la ley del contrato no puede ser o no ha sido elegida por las partes, deberá ser seffalada por la norma de Derecho Internacional Privado, que decidirá si es la ley del lugar 
de celebración, o la del lugar de ejecucion, o la personal común de los contratantes, etc $c_{\circ}$ la aplicable al contrato.

b) El segundo método consiste en solucionar el problema contractual internacional por medio de un derecho sustantivo supranacional, elaborado por los países especialmente para solucionar el fondo de todos los contratos internacionales entre particulares. Esta solución, aunque teóricamente muy aceptable (pues resuelve problemas internacionales privados con un sólo derecho que es a la vez internacional y privado) resulta impracticable en la comunidad internacional actual, a pesar de los meritorios esfuerzos parciales para llevarla a cabo, por lo que postergaremos su análisis.

Por otra parte, cabe recordar que existen ciertos contratos que no se regulan por el régimen general, sino por uno distinto: tal sucede, por ejemplo, cuando es el Estado o las empresas estatales quienes contratan, régimen especial que no es materia de este trabajo.

Teniendo en cuenta lo anterior, pasamos a analizar, en lo que respecta al contrato internacional entre particulares, el sistema plasmado en el Derecho peruano tal como rige actualmente, para compararlo luego con el sistema que prefiere el Proyecto de Reforma del Código Civil.

\section{SISTEMA ACTUAL SOBRE LOS CONTRATOS INTERNACIONALES ENTRE PARTICULARES.}

Las siguientes son las normas pertinentes en vigencia: -Tratado de Montevideo (1889): El Art. 32 del Tratado de Montevideo de 1889 dice: "La ley del lugar donde los contratos deben cumplirse decide si es necesario que hagan por escrito y la calidad del documento correspondiente".

Art. 33 "La misma ley rige:

a) su existencia;

b) su naturaleza;

c) su validez;

d) sus efectos;

e) sus consecuencias;

f) su ejecución; y

g) en suma a todo cuanto concierne a los contratos bajo cualquier aspecto que sea". 
- Código de Bustamante o Tratado de La Habana (1928): En el capítulo I, "De las Obligaciones en General", el Art $169^{\circ}$ se refiere a la naturaleza y efectos de las diversas clases de obligaciones: "La naturaleza y efectos de las diversas clases de obligaciones, así como su extinción, se rigen por la ley de la obligación de que se trata".

En el capítulo II, "De los Contratos en General", el Tratado de La Habana señala las leyes aplicables a diversos aspectos, tipos o elementos del contrato internacional, tales como capacidad contractual, vicios del consentimiento, forma de los contratos, rescisión, nulidad e interpretación del contrato, serfalando cuál debe ser la ley aplicable para cada uno de estos aspectos o elementos del contrato internacional. En estas atribuciones de leyes sustantivas, el Tratado de La Habana utiliza varios factores vinculatorios con los paises: la ley personal, la territorial, el lugar de ejecución del contrato, etc. Admite la autónomía de la voluntad de las partes en el Art. 185 al disponer: "Fuera de las reglas ya establecidas y de las que en adelante se consignan para casos especiales, en los contratos de adhesión se presume aceptada, a falta de voluntad expresa o tácita, la ley del que los ofrece o prepara".

Y el Art. 186 del mismo Código de Bustamante o Tratado de La Habana dice: "En los demás contratos y para el caso previsto en el Art. anterior, se aplicará en primer término la ley personal común de los contratantes y en su defecto la del lugar de celebración".

-Código Civil Peruano (1936): El Art. VII del Título Preliminar del Código Civil Peruano dice: "La naturaleza y efectos de la obligación se rigen por la ley del lugar donde fue contraida".

Como se ve, los tres cuerpos legislativos el Código Civil Peruano y los Tratados de Montevideo y La Habana- toman lugar dentro de la posición llamada "clásica", que es el primer método señalado anteriormente, según el cual, es la norma de Derecho Internacional Privado la que indica a las partes qué ley debe regular su contrato.

Cabe preguntarnos si al disponer el Art. VII del Título Preliminar del Código Civil vigente que la ley del contrato internacional es la del país donde se contrajo la obligación, lo hace de una manera imperativa o lo hace subsidiariamente a la elección de otra ley por las partes contratantes, de modo tal que, en principio, la ley del contrato internacional es la que elijan las partes, y sólo si las partes no eligieron ley alguna, el contrato quedará regulado por la ley del lugar de celebración. 
Hemos percibido ciertas discrepancias en un importante sector de la doctrina respecto a la interpretación del carácter -imperativo o subsidiario- de esta norma, discrepancias que adquieren particular relieve e interés, no sólo por la importancia del asunto, sino por el indiscutible prestigio y reconocida experiencia en el campo de Derecho Internacional Privado de los juristas discrepantes.

Por un lado, interpretan algunos tratadistas, que la ley del lugar de celebración regula el contrato internacional sólo de modo supletorio a la voluntad de las partes; que aún cuando el tex to del artículo no lo señala asi expresamente, es principio de derecho, recogido en nuestra Constitución, que todo lo no prohibido por la ley, está permitido, y como no existe norma alguna que prohiba a los participantes en una relación contractual internacional elegir libremente la ley que desean para que regule su contrato, dicha elección, al no estar prohibida, está permitida. Señalan sin embargo que, obviamente, la ley elegida por las partes deberá guardar alguna vinculación con el contrato que a ella se somete.

Otros autores en cambio, opinan que la disposición del Art. VII, al señalar como ley del contrato a la del lugar donde se contrajo la obligación, es imperativa, y que no suple la voluntad de las partes, pues a éstas no les está permitido elegir la ley que deseen para regular el contrato; que si bien es principio de derecho recogido en nuestra Constitución permitir lo no prohibido por la ley, elegir libremente la ley de un contrato internacional no les está permitido a los individuos, pues se lo prohibe precisamente el Art. VII, al disponer de manera imperativa que el contrato debe regularse por determinada ley, sin advertir en su texto que tal norma tiene carácter supletorio respecto a otra norma no expresada en el Código Civil. ${ }^{3}$

Al margen de estas interpretaciones sobre el carácter subsidiario o imperativo del artículo VII del Título Preliminar del Código Civil vigente, y comparando su texto con el de los artículos respectivos en el Tratado de Montevideo y en el Tratado de La Habana, vemos que los criterios utilizados en cada texto legal, para vincular al contrato internacional con la ley que lo regula, son diferentes: así, mientras el Código Civil prefiere o da mayor importancia al lugar donde se contrajo la obligación, el Tratado de Montevideo considera más adecuado regular el contrato de acuerdo con la ley del país donde debe "cumplirse", y el Código de Bustamante prefiere por otra parte a "la ley de la obligación de que se trata", y a "la ley personal común de los contratantes, y en su defecto la

3. Tal como lo hizo el legislador peruano de 1852, Art. 40, y el Código de Bustamante respecto a los Contratos de Adhesión, Art. 185. 
del lugar de celebración". En suma, los factores de conexión son distintos; sin embargo, el método utilizado es el mismo: ninguna de las normas aludidas permite expresamente a los contratantes elegir la ley del contrato, sino que ésta queda indirectamente determinada por una norma de conflicto.

Cierto es que el Art. 185 del Tratado de La Habana sí permite, de modo expreso, que los contratantes elijan la ley del contrato. Pero debe tomarse en cuenta que tal disposición está referida únicamente a los Contratos de Adhesión, y no a los demás contratos.

Ello porque los Contratos de Adhesión, debido a la universalidad de su uso y a la utilización de formularios contratos-tipo, ... "han ido independizándose de su base legal primitiva, hasta el punto de que en nuestros días no conservan ninguna amarra que los vincule con alguna legislación nacional: con otras palabras, han dejado de ser contratos ingleses, estadounidenses o franceses, para transformarse en contratos auténticamente extranacionales.

Más aún: es frecuente que el contrato-formulario incluya el compromiso de resolver por la vía arbitral todas las controversias que puedan promoverse entre las partes. De este modo el contrato también se independiza de las jurisdicciones nacionales y se libra de que, por la vía judícial, sea sometido a ninguna legislación nacional". 4

E1 mismo Quintín Alfonsín aclara sin embargo, que esta independencia de los contratos formularios es sólo aparente. Deben sustentarse en algún orden jurídico preestablecido, distinto al creado por la voluntad de las partes, pues "la voluntad sólo puede engendrar derechos cuando un orden jurídico la autorice para ello".

Sin embargo, debemos reconocer que en estos Contratos de Adhesión, es costumbre internacional prescindir de las normas de Derecho Internacional Privado nacionales y que ellos tienden a regularse por un derecho "no nacional" circunstancias que explican que, en el Código de Bustamante (Art. 185) tratándose de Contratos de Adhesión, se admitiera que los contratantes elijan la ley aplicable, rigiendo la ley del que los ofrece o prepara, de manera supletoria.

Con la excepción pues, del artículo 185 del Código de Bustamante, respecto sólo a los Contratos de Adhesión, podemos afirmar que ninguno de los Tratados ratificados por el Perú, ni el Código Civil vigente, permiten expresamente que los contratantes elijan la ley del contrato.

Y si interpretamos el Art. VII como norma imperativa, ninguno de los cuerpos legislativos citados, ni expresa ni tácitamente, permitiŕa a los con-

4. Alfonsín Quintín, "Régimen Internacional de los Contratos", Montevideo 1950, pág. 175. 
tratantes la elección de la ley aplicable a contratos que no fueran de adhesión.

Debe también tomarse en cuenta, que tanto el Cỏdigo Civil como los Tratados aludidos no regulan todo el contrato por una sola ley, sino que separan de él diferentes aspectos, para regularlos por distintas leyes. Asi, la capacidad de los contratantes y la forma del contrato no se regulan necesariamente por la misma ley que rige la naturaleza y los efectos del mismo.

Visto el sistema legal vigente actualmente en el Perú, respecto a la ley del contrato internacional, pasamos a analizar lo que dispone el Proyecto de Reforma del Código Civil Peruano.

\section{SISTEMA PROPUESTO POR LA COMISION REFORMADORA DEL CODIGO CIVIL.}

\subsection{Las Partes pueden elegir la Ley del contrato.}

Art. XLIII: "Las obligaciones convencionales se rigen por la ley expresamente elegida por las partes, y en su defecto, por la ley del higar del cumplimiento.

Empero, si deben cumplirse en países distintos se regirán por la ley de la

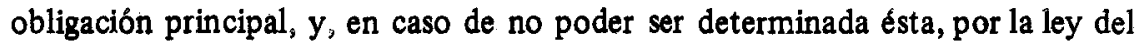
lugar de celebración".

$Y$ el Art. XLIV dice: "La ley que resulte competente, de conformidad con lo dispuesto en el articulo anterior, determina las normas imperativas aplicables y los limites de la autonomia de la voluntad de las part. "s".

Como es fácil advertín, el Proyecto sigue, dentro de la concepción clásica, un método distinto al utilizado por el Código Civil vigente y por los Tratados de Montevideo y de La Habana: según el primer párrafo del Art. LXIII del Pro yecto, ya no es la norma de Derecho Internacional Privado del Juez, la que señala a través de un factor de conexión- cuál es la ley del contrato, sino que es prioritariamente la voluntad de las partes la que selecciona y señala tal ley, posiblemente en el mismo contrato.

Así, el régimen internacional del contrato, en lugar de quedar determinado por una norma de Derecho Internacional Privado referencial, como ocurriría en el Código Civil vigente respecto a los contratos (interpretando el Art VII como norma imperativa y no supletoria de la voluntad de las partes), y en el mismo Proyecto respecto a otras categorías (bienes, sucesiones, familia, etc.) puede quedar determinado directamente por los mismos interesados. 
Dos consecuencias saltan a la vista, con esta innovación:

1) Que la pluralidad dispositiva ya existente y poco recomendable sobre una misma categoría, no queda suprimida ni disminuida, sino engrosada. Hay un nuevo criterio de elección, y de distinta naturaleza que los citados: la autonomía de la voluntad de las partes, la cual regirá prioritariamente en los contratos que estén bajo el alcance del Título Preliminar del Código Civil, y coexisitirá en el marco de aplicación de los Tratados suscritos por el Perú, con los distintos criterios adoptados en dichos Tratados.

2) Que las partes que celebran un contrato internacional podrán elegir como ley del contrato una que no guarde ninguna vinculación objetiva con las circunstancias de dicho contrato.

Esta segunda consecuencia, sobre todo, resulta interesante, por lo que nos permitimos plantear respecto a ella, las siguientes cuestiones:

Al disponer el Art. XLIII del Proyecto que "las obligaciones convencionales se rigen por la ley expresamente elegida por las partes", no aclara si dicha ley debe o no guardar alguna vinculación objetiva con la obligación convencional de la cual se trate.

Podriamos entonces, en principio, interpretar literalmente el texto de dicho artículo, y considerar que no es necesaria esa relación objetiva entre la obligación y la ley elegida, ya que el tenor del Art. XLIII no la exige.

Dentro de esta hipótesis, y con la finalidad de descubrir el verdadero sentido y espíritu de la norma, pasamos a comentar las consecuencias que esa interpretación acarrearía:

-Si dos contratantes nacionales pueden elegir la ley del contrato internacional que celebran, esta ley elegida puede ser la nacional o una extranjera. Si es la ley nacional no habría problema, pero si es una extranjera, ésta puede en principio ser igual que la peruana (con lo que asimilamos el resultado a la elección directa y expresa de la ley peruana) o ser distinta en sus disposiciones. Si es distinta caben dos alternativas: que tales disposiciones vulneren el orden público nacional $^{5}$ (o las buenas costumbres) o que no lo vulneren. Si lo vulneran, entrará en funcionamiento la excepción de orden público nacional ${ }^{6}$ y tal ley extranjera

5. Principio, función o hecho contenido en normas jurídicas, materiales o referencias (Art. III T.P.C.C. vigente y Art. VII del Proyecto de Título Preliminar del Código Civil).

6. Consistente en que una ley nacional sustituya a una norma que es competente según el Derecho Internacional Privado (Art. X T.P.C.C. vigente y XIV del Proyecto de Título Preliminar del Código Civil). 
no será aplicada por el juez peruano en el territorio nacional; pero si no lo vulnera, el juez peruano deberá aplicar las disposiciones distintas de esa ley extranjera.

Entonces, si la ley extranjera que resulte eregida por las partes puede, sin vulnerar el orden público peruano, ser distinta en sus disposiciones a la ley peruana, es perfectamente posible que los interesados logren, con la aplicación de esa ley extranjera, ventajas que no obtendrían si se aplicara al contrato la ley nacional.

Más aún: resulta difícil aceptar que los contratantes se acogerían libremente a una ley extranjera que les resultara menos provechosa o que fuera igual que la peruana. Si eligen una ley extranjera, es pues, porque les es más permisiva o menos prohibitiva que la nacional.

Nos preguntamos si ésta es, y en esa medida, la libertad que parece conceder a quienes celebran un contrato internacional, el Proyecto de Título Preliminar del Código Civil recientemente publicado, ya que, si bien es cierto que esas ventajas obtenidas al aplicarse al contrato la ley extranjera y no la nacional, serían lícitas por haber sido logradas a través del Derecho Internacional Privado peruano, $\mathrm{y}$ en respeto también al orden público y buenas costumbres del país del juez, no nos parece por otra parte justo que, al celebrar dos peruanos un contrato nacional (aquél con todos sus elementos peruanos) deban someterse nécesaria y obligatoriamente a las disposiciones de la ley sustantiva peruana "ya que en defecto de todo conflicto de leyes nos encontramos fuera del Derecho Internacional" 7 y estamos entonces ante un caso de Derecho Civil interno o estricto que se regulará de acuerdo a las normas contenidas en el Libro de las Obligaciones del Código Civil y demás leyes internas; pero que, tratándose de un contrato internacional, esos mismos contratantes nacionales puedan elegir, entre todas las leyes existentes del mundo (o casi todas) la que mejor convenga a sus intereses, descartando a la peruana.

Este trato privilegiado que se da al contrato internacional ¿no incitará a que las partes "internacionalicen" contratos naturalmente nacionales, introduciendo en ellos algún elemento extranjero de fácil provocación, (celebrándolo en otro país, por ejemplo) a fin de poder elegir una ley distinta a la peruana?

7. Niboyet, J.P.: “Principios de Derecho Internacional Privado". Méjico 1969, pág. 663. 
La autonomía de la voluntad que concede el Proyecto a los particulares que celebran un contrato internacional sería, en verdad, amplísima: rebasaria notoriamente la libertad concedida a los contratantes por el Tratado de Montevideo de 1889, por el Tratado de La Habana, por el Tratado de Montevideo de 1940 y por el Proyecto de Ley de Normas de Derecho Internacional Privado de Venezuela de 1965, cuerpos legislativos que son los "antecedentes inmediatos" 8 del Proyecto en este capítulo II de su Título Preliminar, ya que ninguno de ellos otorga a las partes contratantes la facultad de elegir la ley del contrato, como puede verse en los artículos transcritos anteriormente correspondientes a los Tratados mencionados, y en el tenor de los artículos 29 y 30 del Proyecto de Ley de Normas de Venezuela que transcribimos a continuación:

Art. 29": "Las obligaciones convencionales se rigen por la ley indicada por las partes siempre que exista entre esa ley y la obligación una yinculación in" ternacionalmente admisible".

Art. $30^{\circ}$ : "A falta de indicación válida, las obligaciones convencionales se rigen por la ley con la cual están más directamente vinculadas, en razón de sus características subjetivas y objetivas".

Consideramos muy amplia la libertad concedida a las partes en el Proyecto, dentro del supuesto que analizamos, es decir, de no exigirles vinculación objetiva con el país cuya ley eligen, porque la Comisión pudo optar, en principio, a fin de determinar la ley del contrato internacional, por una de las siguientes soluciones:

1) No permitir que la señalen o elijan las partes, sino imponerles, a través de una norma de conflicto y de manera obligatoria, la sujeción a una ley determinable: la del lugar de celebración del contrato o la del lugar de cumplimiento, o la de la nacionalidad común de los contratantes, etc.

Este método o solución fue propuesto en el segundo Anteproyecto (Art. XIII) y, en el Proyecto del Código Civil peruano (Art. VIII), y parecería ser el recogido en el Código Civil vigente (Art. VII). También regulan de este modo el contrato internacional, entre otros, el legislador argentino (Art. $8^{\circ}$ Título Preliminar del Código Civil), el francés (Art. 1134 del Código Civil), el italiano (Art. $9^{\circ}$ ), el polaco (Art. 8,9), el Restatement Norteamericano, etc.

2) Permitir que las partes elijan la ley del contrato siempre y cuando exista en el caso concreto "alguna" vinculación entre las circunstancias del contrato

8. "Exposición de Motivos del Proyecto del Título Preliminar del Código Civil". Revista de Jurisprudencia Peruana, No 379, Lima, febrero de 1977, pág. 258. 
(excluída la mera voluntad de las partes) y el país cuya ley se ha elegido.

Esta es la solución que adopta el Restatement Norteamericano, Second, 1971 ( $\mathrm{N}^{\circ}$ 187), el Business and Commerce Code of Texas (Art. 1.105 a), el Código Civil español (Art. 10.5), el Uniform Commercial Code (section 1-105) la Ley de Normas venezolana (Arts. $29^{\circ}$ y $30^{\circ}$ ) y otros cuerpos legislativos.

3) Por último, la Comisión pudo permitir a los contratantes elegir la ley del contrato sin imponerles una ley determinable ni exigir ninguna vinculación con el país a cuya ley someten el contrato.

Esta última parecería ser precisamente, la opción tomada por la Comisión Reformadora del Código Civil, pues el Art. XIIII no exige a los contratantes ninguna vinculación determinada con el territorio del país a cuya ley se acogen (como si hacen, en cambio, los Tratados suscritos por el Perú); tampoco les exige "alguna" vinculación (cualquiera) efectiva con el país cuya ley eligen, solución que adoptan varias legislaciones al permitir a las partes "elegir la ley del contrato siempre y cuando exista "alguna" vinculación efectiva con el pais cuya ley eligieron, y que, según un sector de la doctrina nacional, es la recogida en el Código Civil peruano vigente", (Art, VII),

El Proyecto no sólo permite elegir cualquier ley (con las salvedades que respecto a su aplicacion se especifican, y que actuarían como excepciones a la aplicación de tal ley por el juez más que como obstáculos para su elección por las partes) sino que permite también, alegir como competentes a los tribunales peruanos bastando el simple sometimiento expreso o tácito a dicha jurisdiccion (Art. LI), con lo cual queda expedita la vía para que dos extranjeros sometan sus problemas contractuales ante el juez peruano aủn sin tener ninguna otra vinculación con el Perú que el deseo de, al amparo de la norma del Art. XLIII, elegir una ley " $\mathrm{X}$ ", elección que podría prohibirles su Derecho Nacional.

Aparte de las consideraciones precedentes (incitación a que se internacionalicen contratos naturalmente nacionales, dado el trato privilegiado que tendrian los contratos internacionales, y apartamien to del sistema o método empleado en sus propios antecedentes legislativos y en el derecho comparado), suponer que el Proyecto permite a los contratantes elegir una ley errática y completamente ajena al contrato, plantearía serios problemas interpretativos respecto a otras normas contenidas en el mismo Proyecto de Titulo Preliminar, en especial, la relativa a la elusión de la ley competente (Art. XVI del Proyecto) y la relativa a la determinación de la imperatividad de las normas por la ley elegida (Art. XLIV del Proyecto), problemas que analizamos en los puntos 4.2. y 4.3. de este trabajo. 


\subsection{Las partes no pueden eludir la ley competente.}

Al tratar de concordar lo señalado anteriormente con el Art. XVI del Título Preliminar del Código Civil del mismo Proyecto, se nos plantea un segundo interrogante.

El Art. XVI del Título Preliminar del Proyecto dispone: "No producirán efectos en el Perú las situaciones juridicas creadas de conformidad con el derecho extranjero, que eludan frauculentamente la ley peruana competente".

¿En qué casos debe considerar el juez que se ha "eludido fraudulentamente" la ley peruana competente? ¿Cuándo es "competente" (a los contratos internacionales) la ley peruana?

Sería difícil comprender en qué puede consistir esta elustón fraudulenta de la ley peruana si cuando dos personas eligen una ley extranjera y descartan la nacional harían ello amparadas y autorizadas por el mismo derecho peruano, (Art. XLIII), el cual deberfa congruentemente, reconocer las "situaciones jurídicas creadas de conformidad con esa ley extranjera".

Los contratos internacionales pueden: A) tener vinculaciones naturales con el Perú, y B) pueden no tenerlas. En el primer supuesto (A), las partes podrían elegir otra ley que no sea la peruana como ley del contrato (Art. XIIII) y en el segundo supuesto (B), podrían elegir a la ley peruana como la aplicable al contrato. Analizando los siguientes supuestos, veremos cómo se dificulta la tipificación del fraude a la ley peruana o a la ley extranjera:

A) Un contrato vinculado al Perú y al pais $\mathrm{Z}$, pero sin ninguna vinculación con el país $X$. En este supuesto las partes podrán acordar como ley del contrato: 1) a la peruana; 2) a la del país $Z$; 3) a la de un tercer pais (X).

B) Un contrato vinculado a los países $\mathrm{X}$ y $\mathrm{Z}$ pero no vinculado al Perí, en el que se acuerda sometimiento a los tribunales peruanos. En este caso se podrá pactar como ley del contrato: 1) la de $\mathrm{X} \circ \mathrm{Z} ; 2$ ) la peruana (que seria la lex fori), o 3) la de un tercer país, ajeno a la relación contractual y al pais del foro.

¿Deberían nuestros Tribunales considerar que ha habido fraude a la ley peruana en el caso A2, cuando, estando vinculado el contrato al Perí y al país $Z$ se prefiere elegir la ley del país $Z$ y descartar la peruana? $Y$ ien el caso A3, cuando estando vinculado el contrato a la ley peruana se preflere otra ley completamente ajena al contrato?

¿Considerará el juez peruano que ha habido fraude a la ley del país $\mathrm{X}$ o a la del país $Z$ en el caso B2, cuando las partes optaron por la ley peruana, que resultaba ser la ley del juez, pero, al fin de cuentas, era una ley extrana al contrato y sin ninguna vinculación "natural" con el mismo? ¿Y habra fraude a 
la ley en el caso B3, cuando las partes descartan las leyes de los países involucrados en la relación contractual y descartan también la ley del juez, para elegir una ley exótica y completamente extraña al contrato y al juez? En rigor, tal como aparecen los artículos del Proyecto, ninguno de estos cuatro casos deberfa constituir un fraude a la ley.

En estos cuatro supuestos, el mecanismo del Derecho Internacional Privado peruano propuesto en el Proyecto, habría permitido a los contratantes elegir la ley que deseen. Esta elección, aún cuando recayera en una ley extranjera, serf́a pues lícita para el derecho peruano, y sus consecuencias deberían aceptarse, porque si los contratos internacionales no tienen una ley obligatoriamente aplicable, no tienen tampoco una ley técnicamente "eludible".

Indudablemente el caso más próximo a configurar un fraude a la ley peruana (foro) es el A3 pues la evadida es la ley peruana vinculada al contrato (siendo el Perú el país del foro) y la elegida una ley extranjera que no tiene ninguna vinculación objetiva con el contrato; aún en este caso extremo notamos sin embargo una contradicción entre los dispuesto en el Art. XVI (fraude a la ley peruana) y lo presumiblemente dispuesto en el Art. XLIII (Libertad en la elección de la ley del contrato), porque, como lo demuestra Quintín Alfon sín ${ }^{9}$, una de estas dos hipótesis debe ser cierta: a) o existe una ley obligatoriamente "competente" al contrato internacional o b) no existe ninguna ley obligatoriamente "competente" al contrato internacional.

En el primer supuesto, si existe esa ley obligatoria al contrato, no puede haber fraude pues las partes carecen de libertad para elegir o provocar la aplicación de otra ley, fraudulentamente. En el segundo supuesto, si no existe una ley obligatoria al contrato, entonces tampoco es posible el fraude, pues no hay ninguna ley que evadir ya que las partes gozan de completa autonomía para. elegir la que deseen.

Cabría preguntarnos, entonces, cuáles son, respecto a los contratos, los casos de "elusión fraudulenta de la ley peruana competente" a que se refiere el Art. XVI del Proyecto, si en los contratos internacionales no habría, en virtud del Art. XLIII del mismo Proyecto, ninguna ley obligatoriamente competente.

9: Op: cit: pdo: 72: 
4.3. La ley elegida determina la imperatividad de las Normas y los límites de la libertad de contratación.

Podría tal vez explicarse el supuesto contenido del Art. XLIII, es decir, la amplia autonomía de la voluntad concedida a las partes, con el argumento siguiente: "la ley elegida por las partes suple la redacción en el contrato de tantas cláusulas como artículos tenga esa ley".

Así como en los contratos nacionales las partes gozan de libertad de estipulación - dentro del marco de limitaciones imperativas peruanas - también en los contratos internacionales las partes pueden estipular con amplia libertad cualquier cláusula, dentro de ese mismo marco limitativo: es sólo por facilidad formal, que se refieren a una ley determinada, en lugar de transcribir a su contrato todo el contenido de dicha ley,

No se tratarfa, entonces, de descartar o evadir la ley peruana, sino de pactar numerosas cláusulas a través de un método sintético (la ley del país X) y en ejercicio del derecho de libre estipulación que en los contratos tanto nacionales como internacionales, concede a los particulares la ley peruana, pero, claro está, dentro de un marco limitativo conformado por las disposiciones imperativas de la ley peruana, las mismas que no podrán ser modificadas por la voluntad de los contratantes.

Pero este argumento pierde toda su base (que es el respeto de las normas imperativas de la ley peruana) al disponer el Art. XLIV del mismo Proyecto que "La ley que resulte competente, de conformidad con lo dispuesto en el artículo anterior, determina las normas imperativas aplicables y los límites de la autonomía de la voluntad de las partes", pues, según parece, la ley que resulte competente (la elegida por las partes de modo expreso) es la única que determina las normas imperativas aplicables al contrato.

Creemos conveniente meditar en que si esa ley pudo ser elegida, fue precisamente porque la ley nacional permitía a las partes contratantes esa elección (Art. XLIII), y "para que las partes puedan, en virtud de la libertad de contratación, elegir la ley del contrato, es preciso que el contrato tenga ya una ley: justamente la ley que regula la libertad de contratación de las partes". 10

La nueva ley no debería pues, a) vulnerar las normas imperativas de la ley peruana, ni b) modificar el alcance de la autonomía de la voluntad concedida a las partes por la ley peruana.

10. Brocher, citado por Quintín Alfonsín, "Régimen Internacional de los Contratos", Montevideo 1950, pag, 20. 
a) La ley elegida no debe vulnerar las normas imperativas de la ley peruana.

El Art. XLIV agravaría la incongruencia entre la autorización del Art. XIIII de elegir una ley extranjera, y la prohibición del Art. XVI de eludir la peruana e invalida el argumento que trataba de justificar la elección de una ley extrafia al contrato en la libertad de estipulación a través del método sintético ("la ley Z" en lugar de tantas cláusulas contractuales como artículos tiene la ley), cuando cede al legislador extranjero (en caso de resultar elegida una ley extranjera) la determinación de las normas imperativas que deberán ser observadas por los contratantes; no sólo cabría pactar una ley completamente extraña al contrato para que lo regule, sino que podría elegise una by que califique como no imperativas, a las normas peruanas que para los contratos nacionales sí tienen ese carácter.

Frente a lo dispuesto por el Art. XIIV, si la ley extranjera elegida, que será la que determine la imperatividad de las normas, sefiala que están permitidas ciertas cláusulas o convenciones prohibidas de manera imperativa en la ley peruana ¿Habrá fraude a la ley peruana cuando dos personas celebran pactos de esta naturaleza? Por ejemplo, ¿se convertiría en lícito el contrato de préstamo con intereses altísimos, permitidos por la ley "elegida"? ¿Bastaríá someterse a una ley extranjera librecambista para despercudirse de las leyes peruanas sobre la materia? ¿Podrá pactarse cláusulas de no responsabilidad en los contratos de transporte? En primer lugar el derecho peruano admitió la elección de esa ley extranjera más permisiva (Art. XLIII), y en segundc lugar, cedio al legislador extranjero la calificación de la imperatividad de las normas (Art. XIIV) ... ¿Por qué ha de haber fraude inclusive en esa hipótesis? ; o es que el Art. XVI, cuando prescribe el fraude a la ley peruana no se está refiriendo a la categoría contractual?

Que las disposiciones de la ley elegida no deben vulnerar la ley nacional - la que permitió a los contratantes elegir otra - ha sido el criterio recogido en el Restatement, Second, Conflict of Laws (1971):

$\left.N^{\circ} 187,1\right)$ "La ley del estado elegida por las partes para regular sus derechos y obligaciones contractuales será aplicada si el asunto del que se trata hubiera podido ser resuelto por medio de una cláusula expresa en el mismo contrato, relativa a dicho asunto". ${ }^{11}$ Es decir, el contrato debe respetar la ley

11. En Reese, Willis and Rosemberg, Maurice, "Conflict of Laws", 6th, edition, 1971, pág. 622. 
que le permite elegir otra. Esta otra queda sometida a la primera, pues solo se aplica en cuanto sus disposiciones esten permitidas por aquella. De este modo, es imposible hablar de fraude a la ley, pues no se evade, sino que se respeta, a la ley nacional que concedió a las partes la libertad de optar por una de otro paŕs ${ }^{12}$

La fórmula de Restatement, Second, descarta también la duda sobre si todos los aspectos o elementos del contrato pueden ser regulados por la ley elegida por las partes. El Proyecto de Título Preliminar peruano, dentro del sentido interpretativo que hemos tomado, permitirfa plantearnos, en cambio, interrogantes como las siguientes: ¿Podría un peruano demasiado joven para contratar válidamente en el Perú revestirse por sí solo de capacidad contractual en virtud de una cláusula que someta al contrato a una ley extranjera que lo declara capaz? ¿Pueden las partes regular la validez del contrato por la ley que eligieron en una cláusula de dicho contrato? ¿Pueden las partes cambiar la ley ya elegida, o una vez realizada la elección de la ley quedan irremediablemente sometidas a ella, sin que tenga ya validez el principio de la autonomfa de la voluntad?

b) La ley elegida no debe modificar el alcance de la autonomía de la voluntad de las partes.

Hemos supuesto que el Proyecto respeta el principio de la autonomía de la voluntad y sabemos que este principio significa lo siguiente: como las personas son autónomas para contratar, puesto que crean por propia voluntad las normas del contrato que celebran, el contrato depende del arbitrio de las personas en dos respectos: $1^{\mathrm{o}}$ porque es la voluntad concordante de ambas partes lo que da origen al contrato (el consentimiento), y $2^{\circ}$ porque es ella quien establece el contenido del contrato (lo consentido), es decir, el objeto, el precio, el plazo . . . y todos los efectos en que las partes consienten. Cada contrato es, por estas circunstancias, un trasunto de la voluntad de las partes, por lo cual reconocer y respetar el contrato equivale a reconocer y respetar lo que las partes estipularon a su arbitrio. Ahora bien: el sistema de la autonomia de la voluntad sostiene que la voluntad de las partes debe ser respetada incluso cuando lo estipulado por ellas consiste en que el contrato sea regulado por tal o cual ley. ${ }^{13}$

12. “¿Pero qué ley es ésta que se teme evadir? Todas las normas prohibitivas y restrictivas de la ley elegida por las partes, se aplican ... y son tambión aplicables todas las normas prohibitivas y restrictivas del foro". R heinstein of Falconbridge, "Essays on the Conflict of Laws" (1947), pág. 57.

13. Alfonsín Quintín, Op. cit. pág. 14. 
El Art. XLIII recogería, pues, el principio de la Autonomía de la voluntad, ya que permite que el contrato sea regulado por la ley que las partes elijan.

Pero el Proyecto dispone, además, que esa ley elegida es la que fija los limites a la autonomia de la voluntad de las partes (en el Art. XLIV), con lo que reparamos en esta incongruencia: "las partes, en el proceso de elegir una ley, deben apoyarse en lo dispuesto por esa ley que van a elegir". Además esa misma ley, la elegida, podría prohibir a los individuos elegir la ley del contrato, con lo cual se descalificaría a sí misma. En dicho supuesto, o no aplicamos la ley elegida por las partes (desconociendo el principio de la autonomía de la voluntad recogido en el Art. XLIII), o aplicamos la ley elegida solo en la parte que no limita a dicho principio, (vulnerando lo dispuesto en el Art. XLIV, es decir, que es la ley elegida la que determina la imperatividad de las normas).

\section{SUGERENCIAS}

En definitiva, nuestros comentarios respecto al régimen optado por la Comisión Reformadora del Código Civil para regular la ley del contrato internacional entre particulares, pueden resumirse de esta manera:

Aparentemente, el texto del Art. XLIII del Proyecto de Título Preliminar del Código Civil autoriza a las partes a que sometan el contrato a una ley completamente ajena y extraña al mismo ya que no exige expresamente que sea necesaria una vinculación objetiva entre la relación contractual y el país cuya ley eligen las partes.

Se apartaría asi del criterio plasmado en los antecedentes legislativos inmediatos del Proyecto, y de los sistemas preferidos en Derecho Comparado, respecto a la determinación de la ley aplicable al contrato internacional entre particulares.

Por otra parte, el Art. XLIII facultaría a los contratantes a que coloquen sus intereses particulares por encima de los intereses generales de la Comunidad Internacional.

Además, el Art. XLIII, al permitir a los contratantes que ellos mismos señalen la ley competente, resultaría incompatible con la prohibición de "eludir la ley peruana competente" contenida en el Art. XVI del mismo Proyecto.

Consideramos que debería aclararse el sentido del artículo XLIII del Proyecto, determinándose la ley del contrato internacional, y el reconocimiento de las consecuencias de su aplicación, según y de acuerdo con el grado de fuerza vinculatoria objetiva que dicho contrato guarde con los paises.

Sugerimos, dentro de esta concepción, que se permita a las partes optar por una ley extranjera, siempre que ésta guarde alguna vinculación objetiva con 
la relación contractual; que las partes que elijen una ley extranjera vinculada al contrato, queden sometidas a sus disposiciones imperativas, reconociéndose en el Perú las situaciones juridicas creadas al amparo de dicha ley, siempre que la ley peruana no guarde con la relación contractual una vinculación más estrecha que la ley elegida por los contratantes. ${ }^{14}$

Los Tribunales peruanos cuidarán, a través de las excepciones pertinentes, que no se vulneren las disposiciones de orden público nacional. De esta manera:

- Se le permite a los que celebran un contrato internacional optar por una ley extranjera, pero esa ley debe estar vinculada al contrato;

- Se respeta la ley extranjera así elegida, y sus consecuencias, pero éstas sólo se reconocen si la ley peruana no resultaba más adecuada y apropiada para regular la relación, por guardar con ella mayores vinculaciones;

- Y se protegen las normas imperativas peruanas, al no aplicar la ley extranjera ni reconocer las eonsecuencias de su aplicación, si con ellas se vulnera el orden público peruano.

Se obtendría así un marco legal congruente en sus disposiciones, permisivo y limitativo a la vez, que equilibra la libertad individual de estipulación en el campo internacional, con el resguardo que merecen las normas imperativas nacionales.

14. El Restatement, Second, Conflict of Laws 1971, $\mathrm{N}^{\circ} 187,2$, permite la aplicación de la ley extranjera, y de sus disposiciones contrarias a la nacional, a menos que: a) no exista una real y efectiva vinculación entre el país cuya ley se elije y la relación contractual, o b) que la ley elegida vulnere normas imperativas de una ley que tenga mayor conexión con la relación contractual. 